\title{
Perception of performance management system by academic staff in an open distance learning higher education environment
}

\begin{tabular}{|c|c|}
\hline \multicolumn{2}{|c|}{$\begin{array}{l}\text { Authors: } \\
\text { Esther M. Maimela }^{1} \\
\text { Michael O. Samuel }^{2}\end{array}$} \\
\hline \multirow{2}{*}{\multicolumn{2}{|c|}{$\begin{array}{l}\text { Affiliations: } \\
{ }^{1} \text { Department of Human } \\
\text { Resource Management, } \\
\text { University of South Africa, } \\
\text { South Africa }\end{array}$}} \\
\hline & \\
\hline \multicolumn{2}{|c|}{$\begin{array}{l}{ }^{2} \text { Department of Management } \\
\text { and Human Resource } \\
\text { Management, University of } \\
\text { the Witwatersrand, } \\
\text { South Africa }\end{array}$} \\
\hline \multicolumn{2}{|c|}{$\begin{array}{l}\text { Corresponding author: } \\
\text { Michael Samuel, } \\
\text { olorunjuwon.samuel@wits. } \\
\text { ac.za }\end{array}$} \\
\hline \multicolumn{2}{|c|}{$\begin{array}{l}\text { Dates: } \\
\text { Received: } 14 \text { Jan. } 2016 \\
\text { Accepted: } 02 \text { Sept. } 2016 \\
\text { Published: } 31 \text { Oct. } 2016\end{array}$} \\
\hline \multicolumn{2}{|c|}{$\begin{array}{l}\text { How to cite this article: } \\
\text { Maimela, E.M., \& Samuel, } \\
\text { M.O. (2016). Perception of } \\
\text { performance management } \\
\text { system by academic staff in an } \\
\text { open distance learning higher } \\
\text { education environment. SA } \\
\text { Journal of Human Resource } \\
\text { Management/SA Tydskrif vir } \\
\text { Menslikehulpbronbestuur, } \\
\text { 14(1), a784. http://dx.doi. } \\
\text { org/10.4102/sajhrm. } \\
\text { v14i1.784 }\end{array}$} \\
\hline \multicolumn{2}{|c|}{$\begin{array}{l}\text { Copyright: } \\
\text { (c) 2016. The Authors. } \\
\text { Licensee: AOSIS. This } \\
\text { is licensed under the } \\
\text { Creative Commons } \\
\text { Attribution License. }\end{array}$} \\
\hline \multicolumn{2}{|l|}{ Read online: } \\
\hline 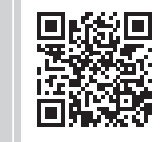 & $\begin{array}{l}\text { Scan this QR } \\
\text { code with your } \\
\text { smart phone or } \\
\text { mobile device } \\
\text { to read online. }\end{array}$ \\
\hline
\end{tabular}

Orientation: Institutions of higher learning in South Africa are fast embracing performance management system (PMS) as a mechanism for the achievement of teaching excellence and enhancement of research productivity. However, literature provided evidence to show that application of PMS in the private sector had failed to drive competition, efficiency and productivity.

Research purpose: The main purpose of this article was to evaluate the perception of academic staff members of an open distance learning institution regarding the implementation of a PMS.

Motivation for the study: PMS as a mechanism through which performance of academics is measured has been described as inconsistent with the long tradition of academic freedom, scholarship and collegiality in the academy. Moreso, previous research on the implementation of PMS was limited to private sector organisations, thus resulting in the dearth of empirical literature relating to its practice in service-driven public sector institutions.

Research design, approach and method: The article adopted a quantitative research approach using census survey methodology. Data were collected from 492 academic staff from the surveyed institution using a self-developed questionnaire that was tested for high content validity with a consolidated Cronbach's alpha value of 0.83 . Data were analysed using a onesample $t$-test because of the one-measurement nature of the variable under investigation.

Main findings: Major findings of the study indicated that respondents were satisfied with the implementation of the PMS by management. However, the payment of performance bonuses was not considered as sufficiently motivating, thus necessitating a pragmatic review by management.

Practical/managerial implications: The findings of this article provided a practical guide to managers on the implementation and management of PMS as an employee performance reward mechanism in non-profit and service-oriented organisations.

Contribution: This article provided an incremental contribution to the body of literature in the broad field of management and a further advancement of existing knowledge in the sub-field of performance management system.

\section{Introduction}

Globalisation-induced competition has substantially increased the necessity for organisational managers to develop sustainable human resource (HR) strategies that are capable of optimising business performance (Imran, Arif, Cheema \& Azeem, 2014). One such HR strategy is the development of performance management system (PMS). PMS has been variously described by authors as a combination of a number of functions and processes that have been carefully planned and carried out with the intention of achieving predetermined organisational objectives through employee's work performance (Aguinis, 2013; Armstrong, 2009; Hawke, 2012; Sousa, De Nijs \& Hendriks, 2010; Taticchi, Balachandran \& Tonelli, 2012). Therefore, performance management is considered as an integral and inalienable managerial function in any organisational setting (Islam \& Rasad, 2006). This is more so as organisational managers attempt to devise an objective criteria that measures the performance of employees, both as individuals and group and to determine the extent to which such performances have contributed to the overall achievement of business effectiveness (Stanton \& Navenkis, 2011). PMS provides a mechanism through which organisational rewards are objectively matched with individual employee's contribution to the achievement of organisational goals. The complexity involved in the design and implementation of this performance measurement 
criteria has over the years posed a challenging operational consideration for HR managers (Saeed \& Shahbaz, 2011). Notwithstanding the complexity and challenges that are associated with this performance management activity, it remains the responsibility of management to provide a link between organisational effectiveness and employee performance.

Many authors (e.g. Bowman, 1994; Daley, 1998; Fox \& Shirkey, 1997; Perry, 1991) have questioned the continued relevance and use of the merit rating or performance appraisal system as an objective performance evaluation technique. Merit rating or performance appraisal is a systematic and periodic evaluation of individual employees' value to the organisation in comparison to his or her colleagues (Junais, 2012; Toppo \& Prusty, 2012). This criticism has accelerated the adoption of PMS as a more objective alternative in providing an integrated and continuous approach to the management of employee performance (Armstrong, 2009). Further preference for the adoption of PMS by managers is motivated by the ever increasing complexity in the management of business, which require a dynamic process of monitoring and evaluation (Willaert \& Willems, 2006). Therefore, this complex and dynamic operating business environment requires a strategic and integrated performance management process that could assist the organisation to gain competitive advantage. The integrated approach involves the integration of other HR functions such as recruitment and selection, performance evaluation, training and development and remuneration (Pieters, 2009). The overall objective of the integrated approach is to establish a strategic alignment between a functional PMS and the overall organisational goals.

The motivation for the introduction of PMS in the higher education sector could perhaps be linked directly to increasing pressure from government for universities to increase both student throughput and research output. The introduction of performance incentive system (subsidy) by government in the higher education sector in South Africa has no doubt provided an unintended impetus for competition in the academy. Because incentivised performance management was alien to the educational sector, management of universities imported the prevailing performance management practices in the private sector. A number of performance management practices operating in the private sector include the 'Integrated Performance Management System' and '360 Degree Performance Management System'. Notwithstanding the use of PMS in the private sector as a measure of productivity and competitive advantage, documented evidence suggests that the approach was not effective in achieving these objectives (Moullakis, cited in Karim, 2015; Karuhanga, 2010; Hainess \& St-Onge, 2011). However, management of universities seems to disregard such available evidence, consciously or unconsciously.

One noticeable shortcoming of performance management programmes is the assumption by the designers that one programme works well across entities without necessarily taking into consideration the peculiarities of individual organisations. This ambitious and erroneous belief most often signifies the beginning of failure for such programmes. In order to avoid such a design failure, Kandula (2006) recommended an organisation-specific PMS that considers individual organisation's peculiarities such as internal environment, business strategy, strengths and weaknesses, vision and mission. The design pitfall that characterises adoption of performance management programmes partly motivated this study, as the adoption of PMS in the private sector may not necessarily achieve the same in a serviceoriented academic institution.

While the main business of universities is to create and impart knowledge and disseminate scholarly ideas through research, private sector organisations are business oriented with the sole objective of capital accumulation and profit maximisation (Hudzik, 2011). However, research publication and graduate throughputs in South African universities attract some form of monetary subsidies from government. This subsidy in some ways serves as a third-stream income for universities; and this also trickles down to research-active academics, thus making the business of research publication a commercial enterprise rather than scholarly engagement (Bogt \& Scapens, 2011; Hill, 2010; Flaniken, 2009).

\section{Research problem}

The introduction of PMS as a performance monitoring tool for academics has been considered to be in conflict with the tradition of academic freedom, scholarship and collegiality (Parsons \& Slabbert, 2001; Tam, 2008). Previous studies (e.g. Solomons, 2006; Willaert \& Willems, 2006) relating to the practice of PMS were conducted in the private sector, thus resulting in the dearth of empirical literature relating to PMS practice in service-driven public sector institutions. Furthermore, existing literature revealed that most of the studies on the impact of PMS in higher education were conducted in universities where the mode of teaching involves face-to-face interactive lecture sessions between lecturers and students. Such teaching methodology is different from those applied in open distance learning (ODL) universities where teaching and learning take place through correspondence and in the absence of a physical interaction between students and lecturers. A salient problem arising from the introduction of performance management programmes by different organisations is that such programmes are not compatible with the organisational culture and this often shapes the perceptions of employees (Kandula, 2006). For example, issues around organisational culture, values, tradition, mission and vision differ from one organisation to the next and are most distinguished between profit- and service-oriented organisations. Similarly, the operating environment in a face-to-face teaching university is different from that of an ODL University in terms of performance measurement and management. The distinctions between the mode of operation in ODL institutions and other universities partly inform the conduct of the present study. 
This is with the aim of avoiding a designer failure - that is, tendency of a one-system-fits-all approach - in the introduction of a performance management programme.

\section{Study objective and research questions}

It is against the background of the research problem described in the above section that this article sought to evaluate the perception of academic staff members in the institution under study regarding the implementation of a PMS. In order to achieve this broad primary objective, the researchers formulated the following overarching research question: what are the perceptions and experiences of academic staff at a South African ODLUniversity regarding the implementation of a PMS? The following section provides both literature overview as well as theoretical framework for the article.

\section{Literature overview}

\section{Performance management system and organisational culture}

The decision to introduce a PMS requires careful consideration by management of the compatibility of the intended change with the prevailing culture and tradition of the organisation (Solomons, 2006). Previous literature (e.g. Bititci, Mendibil, Nudurupati, Garengo \& Turner, 2004; Shields, 2008) argued that the introduction of a PMS is capable of transforming employee values, attitudes and behaviour thus leading to an eventual change in the overall culture of the organisation. Culture evolves over a long period of time, and once established, becomes extremely difficult to change (Hatch \& Cunliffe, 2006). An effective change in organisational culture involves changes in policies and procedures, and most important, managing the subconscious unaware assumptions and values which guide people's behaviour (Kandula, 2006; Ogbonna, 2007). This may imply that changes in the physical structures of the organisation are not capable of transforming established organisational culture and behaviour of academic staff. What is required for an effective change in behaviour is a reorientation of the thinking process from the old ways to embrace a new way of doing things. Therefore, changing existing organisational culture and employees' behaviour are crucial for the successful implementation of PMS (Robinson, Carrillo, Anumba \& A-Ghassani, 2005). The authors emphasised the traumatic experience that is associated with change, and this explains why employees' resistance to change should be expected by management as a natural phenomenon.

\section{Workload model in open distance learning institutions}

The South African Institute for Distance Education (SAIDE, 2009) described an ODL system of education as an approach that seeks to remove all unnecessary physical barriers to learning in order to provide more people with a meaningful platform to acquire higher education. The teaching methodology in the ODL University (explained in the preceding literature) does have implication for the workload model of academics. Performance of their primary responsibility of teaching involves substantial administrative engagement unlike their contemporaries in conventional universities. These cumbersome administrative duties impact significantly on the time available to conduct research by ODL academics, yet research productivity accounts for a substantial amount of subsidy accruable to the university from the Department of Higher Education.

The administrative bottleneck in the ODL course delivery is embedded in the design of the system, and this should not be compromised at the expense of research productivity. Tutors are employed in the ODL system to provide academic support for learners (Maimela, 2015). These tutors are managed by academic staff of the institution. This places additional responsibility on lecturers and this has further implication on their research productivity. However, the impact of tutor management by lecturers in the ODL system has been described as a negligible fraction of lecturers' workload as study and other learning resources are distributed to learners using Internet facilities (SAIDE, 2009). This description may not be totally accurate as teaching and instructions through the distance education system involves the use of printed course materials and telecommunication devices such as twitter, podcasts, and smart phones. All these processes are managed by academic staff. As a result, academics in ODL institutions are office bound with fixed working hours, expending most of their productive time developing study materials and responding to student enquiries on a daily basis. This no doubt impacts negatively on the amount of time available for research, which is a critical component of the 'Key Performance Area' in the PMS.

\section{Does employee perception matter in the performance management system process?}

The simple answer to the above question is 'yes'. The explanation for this answer is that management needs to enlist the understanding and cooperation of the category of employees who would be affected by the operationalisation of the PMS. For this to happen, recipients of PMS must perceive the programme to be a fair, just and equitable one (Farndale, Van Ruiten, Kelliher \& Hope-Hailey, 2011; Islam \& Rasad, 2005; Kavanagh, Benson \& Brown, 2007; Luthra \& Jain, 2012). It is only then that employees return the intended benefits of PMS to management. One can also reasonably assume that employees will not likely embrace a PMS that they perceived to be biased, unfair and lacking equity in the distribution of organisational outcomes (e.g. promotion, salary increment, research incentives). The whole essence of balancing employee input with reward output is located within the concept of organisational justice (Baldwin, 2006; Greenberg, 1990). Literature of organisational justice was derived from Stacey Adams' equity theory (1963), which postulates an input-output ratio comparison by an individual employee with those of his or her colleagues and reacts based on the outcome of the assessment. Employees who perceive injustice in the input-output ratio will likely embark on withdrawal activities that include reduced productivity, lateness, sabotage or resignation from the organisation (Schultz, Bagraim, Potgieter, Viedge \& Werner, 2003). 


\section{Monitoring of academic staff performance: A new trend}

Managers of higher education institutions now expect employees in the sector (particularly academics) to embrace organisational innovation practice that is typical of the private sector organisations (Hill, 2010; Parsons \& Slabbert, 2004; Türk, 2007). Such expectation is informed by the need to ensure efficiency in the operations of higher education institutions in South Africa. This involves a systemic monitoring and measuring of academics' work performance and outputs. Ironically, such practice conflicts directly with the age-long established tradition of a self-defining work mechanism expressed within the context of autonomy and academic freedom (Pityana, 2004). However, the implementation of PMS in many institutions of higher learning suggests that work roles of academics are being defined by managers based on values and purposes that are dictated by market economy rather than the academic enterprise (Pityana, 2004). This management tendency has been described as the 'new public management', which is oriented towards outcomes and efficiency through better management of public budget (Shishkina, 2008; Zeleza, 2012). The introduction of this managerial approach in higher education sector could be problematic as managing a university is quite different from that of government ministries (Shishkina, 2008). Therefore, introduction of this new found management practice in the university system should be carefully considered as this could severely compromise the principle of work autonomy and academic freedom.

Management of higher education institutions have been under pressure by the higher education authority to increase student enrolment and research productivity without a corresponding increase in budgetary allocation (Parsons \& Slabbert, 2004; Ruben, 2004). A possible way of achieving government's demand by management is the implementation of PMS which measures work outputs in quantitative terms. However, available studies indicated that operationalisation of the PMS in higher education institutions around the world is challenging (Mapesela \& Strydom, 2004; Osei-Owusu, 2013; Tam, 2008). Further literature resists any attempt to commercialise academic institutions whose social objective is the production and dissemination of knowledge through research and teaching (Shishkina, 2008).

The outcome of a study conducted by Mapesela and Strydom (2004) in three higher education institutions in South Africa regarding the introduction and development of PMS highlighted the tension between collegiality and managerialism as it affects academic freedom. This tension, according to the authors, reflects the outcome in the business sector and such outcome is difficult to manage in a university system that is complex and diverse (Tam, 2008). Similarly, Martz, McKenna and Siegall (2001) argue that one of the most controversial issues associated with designing a workable PMS for academics is to first determine the content of the scholarly activities that would be incorporated into it (e.g. teaching, research, community engagement, academic citizenship).
Therefore, for PMS to be effective in the higher education environment, a typical business performance management model and approach needs to be adapted to the peculiarities of higher education institutions.

Academics have contested the validity of PMS arguing that it failed to measure all the activities it is supposed to measure (Pienaar \& Bester, 2007). Respondents in the study by Pienaar and Bester highlighted overtly the preference of research over teaching by university management thus resulting in a dilemma for academics as to which of the academic activities teaching or research - to prioritise. Therefore, for the study participants, the PMS constitutes unnecessary barrier to their career progression. Therefore, PMS should be designed to incorporate a full range of academic activities performed by academic staff in order for it to be well accepted and trusted. An effective PMS should account for the complex linkages between task performance and time factor. Based on a comparative study of some universities in the United States, United Kingdom, Nigeria, Australia and South Africa, Molefe (2010) concluded that introduction of PMS will likely be resisted by academics if its performance assessment criteria do not take into account the following broad issues:

- teaching workload or distribution of workload between members of the departments

- results of student evaluation based on an acceptable format used by the faculty

- student numbers per course research output with emphasis on accredited output

- corporate citizenship which encompasses service to the community without compensation.

The debate around the implementation of the PMS in academic institutions has been a balanced one. While some academics argued that the approach is anti-thetical to the academic culture, others submitted that PMS is capable of improving performance in the higher education system. For example, Taylor (2001) emphasises that the introduction of performance indicators in an academic institution can motivate its members to work harder, especially academics who are inclined and motivated by extrinsic rewards such as money and other financial rewards. However, people who are intrinsically motivated would be disinclined to support the PMS (Ryan \& Deci, 2000). Instead, they would be motivated by factors such as recognition or quality of life factors such as leisure and holiday with family and friends.

In furtherance of the early study, Molefe (2012:5265) developed a model that depicts aspects of performance management that were both theoretically and empirically considered as important aspects for measuring the work of academics (see Figure 1).

Molefe's model (Figure 1) suggests that a feasible and workable performance management for academics should consider competencies such as knowledge and subject mastery, communication skills, student-lecturer relationship, workload and the reward mechanism. Molefe (2012) 


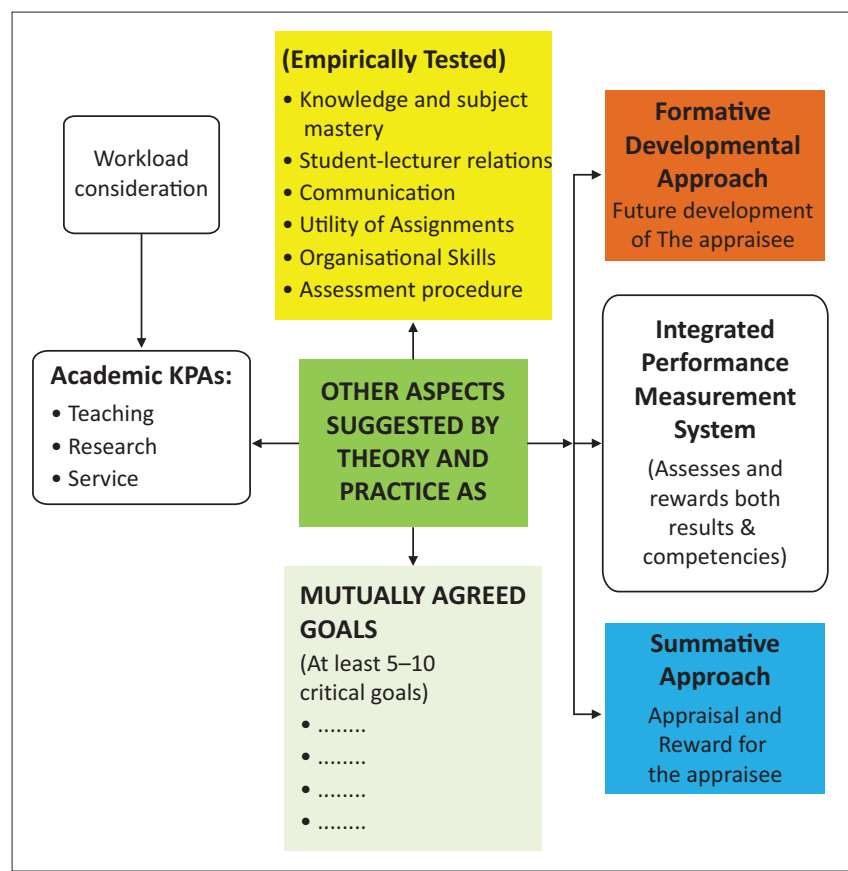

Source: Molefe, G.N. (2012). Performance measurement model and academic staff: A survey at selected universities in South Africa and abroad. African Journal of Business Management, 6(15), 5265

FIGURE 1: Conceptual model of performance measurement for lecturers.

contended that a PMS that considers all the stipulated competencies will likely be successful as both financial and non-financial rewards have been incorporated.

\section{Theoretical framework for the study}

Performance management literature is broadly conceptualised within the framework of motivational theories as Kandula (2006) argued that unless the motivational composition of individuals is correctly understood and managed effectively, no performance could ever be successful. Therefore, performance excellence comes from people who are well motivated. This treatise is underpinned by the goal-setting theory and expectancy theories (Atkinson \& Shaw, 2006) respectively.

Goal-setting theory is essentially premised on the understanding that some individuals perform better when specific goals are set as there is the tendency for them to remain focussed and expend additional efforts in order to achieve set goals (Locke \& Latham, 1990). The theory is predicated on the argument that (1) individuals have different goals, (2) act to achieve such goals if there is a chance of succeeding and (3) the value of the goal affects the level of motivation (Locke \& Latham, 1990). The theory further postulates that not only does assigning specific goals to individuals or teams result in enhancement of performance but also enhancing goal acceptance through employee involvement and increasing the challenges of goals leads to increased motivation and improved performance. Apart from being challenging, goals should also be clearly stipulated and feedback mechanism installed. Involving employees in the goal-setting process is crucial in order for performance management to be effective and successful.
Vroom (1964) posited the expectancy theory on three basic factors: valence, instrumentality and expectancy. Valence refers to the value, that is, the attractiveness of the task outcomes (e.g. rewards); instrumentality is the degree of expectation that improved job performance will lead to the desired task outcomes and the expectation that increased effort is perceived to lead to increased job performance (outcomes). Therefore, the greater the value of a set of rewards and higher the probability that receiving each of these rewards depends upon effort, the greater the effort that will be expended in achieving the set outcome. The applicability of the expectancy theory found empirical support in a study conducted by Aguinis (2013), which demonstrated that PMSs are more effective when results (performance) are directly tied to the reward system (valence).

\section{Research methodology Research design, population and sampling}

The article adopted the case study research design using the quantitative approach (Bryman \& Bell, 2011). Case study design was more appropriate because the study was limited to a single organisation. A census survey was used to collect primary data from and about every individual in the population (Floyd \& Fowler, 2014). The distinguishing factor between census survey and sample survey is that the former (census survey) collects data from every member of the population while the latter (sample survey) collects data only from some members of the population (Chawla, Chindra \& Pandey, 2013; Harding, 2006). The census survey strategy is enhanced in the study because of the homogeneous nature of the population (i.e. all academics) irrespective of their academic positions or titles within the institution. Structured questionnaire was therefore administered to a target population of 1775 as contained in the sampling frame (Bryman \& Bell, 2011) obtained from the case university database. Questionnaires were distributed using the institutional email address of all the participants.

\section{Measuring instrument}

A self-constructed questionnaire comprising four sections with each section measured on a 5-point Likert scale (anchored on $1=$ 'strongly disagree' to $5=$ 'strongly agree') was employed in gathering primary information from the participants (Cooper \& Schindler 2001; Tustin, Lighelm, Martins \& Van Wyk, 2005). The questionnaire items were derived from extensive review of performance management literature in order to achieve content validity (Bryman \& Bell, 2011) while the questionnaire items were also pre-tested in a pilot study comprising 11 academic subject matter experts who were purposively selected from the case institution. Reliability test was performed on the measuring instrument using the Cronbach's alpha coefficient and the following alpha values were obtained: Section A comprises 7 items with a Cronbach's alpha value of 0.822; Section B comprises 10 items with a Cronbach's alpha value of 0.911; Section C comprises 8 items with a Cronbach's alpha value of 0.693 and Section D comprises 8 items with a Cronbach's 
alpha value of 0.895. Each section of the measuring instrument achieved the reliability threshold of 0.70 as recommended by Nunnally (1978), thus establishing the internal consistency of the instrument. Similarly, the average inter-item correlations all exceeded 0.30 , indicating relative homogeneity among items and reflecting the same underlying construct (Hair et al., 2010). Sections A, B, C and D of the measuring instrument were designed, respectively, to measure the following aspects of PMS: awareness and understanding of the PMS; the role of managers in ensuring the effectiveness of the PMS; satisfaction with performance goals and standard setting and satisfaction with performance rating and bonus.

Section E of the questionnaire consists of biographic information of the respondents with the following key demographic distributions: academic staff from professorial to lecturership positions (78\%), research assistants and academic administrators (22\%). Others are female respondents (52.4\%), male respondents $(47.6 \%)$, white respondents $(55.3 \%)$, black respondents, and Indian and mixed-race respondents (44.7\%). The respondents were aged between 20 and 65 years (97\%) with $43 \%$ possessing doctorate degrees while $57 \%$ hold other academic degrees.

Of the 492 questionnaires returned, only 313 were useable. This represents $64 \%$, which is considered adequate for the study.

\section{Data analysis and discussion}

This section consists of interpretation of data as presented in the respective tables (Tables 1-4) and then followed immediately by a discussion of the statistical results. Each table consists of a theme, and each theme comprises a number of separate questions with independent statistical results. As a result of this arrangement, the results, interpretation and discussion were presented together rather than organised into separate sections (data analysis, discussion).

\section{Data analysis}

Data analysis was conducted using a one-sample $t$-test, which is used to test whether a population mean is significantly different from some hypothesised value. It is more useful when one-measurement variable is involved and the researcher wants to compare the mean value of the measurement variable with some theoretical expectations.
The present study measured the perceptions of all academic staff (irrespective of their positions) in case the university considered implementing PMS. This represents a onemeasurement variable. The statistical results and discussion of findings are presented in the following section.

The results present a strong evidence of awareness with a reported mean of $\bar{x}=4.68$ and associated standard deviation $\sigma=0.641$. Further analysis showed a fair perception regarding clear definition and communication of the system to the affected employees $(\bar{x}=3.4$ and $\sigma=1.226 ; \bar{x}=3.34$ and $\sigma=$ 1.266 , respectively).

It is imperative for the management to explain the rationale for introducing a PMS to the affected employees (Aguinis, 2013) as transition from one assessment regime to another requires communication and justification (change management) of the new system in order to re-orientate and assist the employees in understanding and coping with the new system (Ogbonna, 2007). Consultation with respective stakeholders is a key requirement during the design and implementation of a PMS in any organisation. However, the results $(\bar{x} 1.88 \& \sigma 1.166)$ of this article indicate that academics were not consulted during the process and this could lead to the failure of PMS in the institution (Aguinis, 2013). Aguinis emphasised that in order for any PMS to be successful, all stakeholders must be consulted and provided with an opportunity to participate and make input in its development and implementation. This participatory approach provides each party an opportunity for trade-offs and compromise. It is expected that possible aspects of the system that could cause tension during implementation would have been removed at the design stage.

The research study tested the extent to which the design of PMS enabled academics to express the value of their individual contribution towards the institutional goals. The results $(\bar{x}=$ 3.01 and $\sigma=1.312$ ) suggested a slightly poor deviation of respondents from the mean to indicate a neutral position.

These results are inconsistent with recommendations by previous studies (e.g. Aguinis, 2013; Kim, 2011), which emphasised that PMS creates a direct link between employee performance and organisational goals and makes the employee's contribution to the organisation explicit. Therefore, it is a strategic HRs imperative to align and integrate both individual employee's performance and group contributions to the overall effectiveness of the organisation (Stanton \& Nankervis, 2011).

TABLE 1: Results of one-sample t-test statistics for Section A of the measuring instrument.

\begin{tabular}{|c|c|c|c|c|}
\hline $\begin{array}{l}\text { Section A: Awareness and understanding of the performance } \\
\text { management system in your organisation }\end{array}$ & $N$ & Mean, $\bar{x}$ & $\begin{array}{c}\text { Standard } \\
\text { deviation, } \sigma\end{array}$ & $\begin{array}{c}\text { Standard error } \\
\text { of the mean }\end{array}$ \\
\hline Q. Awareness of its existence in the institution & 313 & 4.68 & 0.641 & 0.036 \\
\hline Q. Definition and communication of its purpose by management & 313 & 3.4 & 1.226 & 0.069 \\
\hline Q. Consultation in the design & 313 & 1.88 & 1.166 & 0.066 \\
\hline Q. Understanding of the rationale for its introduction & 313 & 3.34 & 1.266 & 0.072 \\
\hline Q. Assist in expressing values of my contribution to organisational goals & 313 & 3.01 & 1.312 & 0.074 \\
\hline Q. Integration of both individual goals with those of the institution & 313 & 2.88 & 1.302 & 0.074 \\
\hline Q. Purpose of PMS achieved & 313 & 2.4 & 1.252 & 0.071 \\
\hline
\end{tabular}

PMS, performance management system. 
However, contrary to existing literature, majority of the respondents in the present study conceded the failure of PMS to integrate individual academics' goals with that of the institution $(\bar{x}=2.88$ and $\sigma=1.302)$.

The implication of the above finding is explained by Decramer, Christiaens and Vanderstraeten (2007), who noted that institutional goals may sometimes conflict with personal goals, thus resulting in conflict of interests during the system implementation stage. Furthermore, employee performance management generally represents a smaller part of a broader strategic organisational goal. Lack of synergy between individual performance objective and organisational goals may frequently result in tension and lack of cooperation between the different entities (Decramer et al., 2007; Gruman \& Saks, 2011). Respondents were therefore negatively disposed to the effectiveness of the PMS in serving the purpose of its establishment by management. This statement is derived from the statistical evidence $(\bar{x}=2.4$ and $\sigma=1.252)$, which shows that majority of the respondents fall below the mean and a greater deviation from the average position. This finding is consistent with that of Holland (2006), who revealed that only 3 out of 10 employees believed that the performance-review system in their organisations actually assisted in improving their performance towards achieving the organisational goals. Coleman (2012) further argued that it is unrealistic to expect that when a PMS is implemented, employees will automatically and immediately be motivated to perform better.

The role of managers in the implementation of any PMS cannot be overemphasised as they exercise judgement in rating employees' performance. In order to exercise this judgement effectively, managers must be knowledgeable about the rating requirements of the system, and more importantly, be able to objectively justify rating awards to employees who may require such explanation. This study established that a large percentage of academics who responded to the questionnaire do not perceive their reporting line managers to be appropriately qualified in reviewing individual performances $(\bar{x}=3.42$ and $\sigma=1.248)$.

However, the finding on the role of managers in the review of PMS was not supported by Aguinis (2013), who argued that managers are usually in the best position to evaluate employees' performance in relation to strategic organisational goals. The justification is that managers are responsible for operating strategic goals of the organisation and this provides them with the knowledge of individual employee's performance. The ability and knowledge of managers in implementing the PMS was not in doubt in the present study given the statistical results of $\bar{x}=3.45$ and $\sigma=1.168$, respectively. However, strangely, this result was not supported by Flaniken (2009), who found that in most organisations, managers do not receive sufficient performance training and this results in inadequate knowledge with which to rate employee's performance. There was no explicit indication to suggest that managers were specifically trained in the management of PMS, but respondents in this study did not seem to have problems regarding the ability or knowledge of their managers in implementing the PMS. Notwithstanding the statistical outcome in the present study, any PMS requires targeted performance management training for managers in order to guarantee success (Haines \& St-Onge, 2012).

Application of the PMS by line managers should be guided by the relevant institutional policy. To this end, we sought to know from the respondents if this was the case. Although a high percentage of the respondents agreed with this statement $(\bar{x}=3.49)$, this outcome could not be described as truly representative of the respondents with a $\sigma=1.115$.

Although information regarding the PMS is conspicuous and easily accessible via the institution's Intranet, a reasonable number of respondents could not ascertain whether managers applied the system in accordance with the institutional policy. This, perhaps, could account for the divergent degree of standard deviation recorded $(\sigma=1.115)$. The finding in this study thus reflects a recommendation by Aguinis (2013) that performance management policy must be developed and implemented in such a way that it provides clear guidance to managers and employees on how to deal with performance and capability issues.

Our findings regarding the objectivity of the ratings and quality of feedbacks received from their managers suggest that majority of the respondents considered the rating outcomes as subjective and not objectively representing their performance. Similarly, feedback provided by their managers was neither constructive nor progressive.

TABLE 2: Results of one-sample $t$-test statistics for Section B of the measuring instrument.

\begin{tabular}{|c|c|c|c|c|}
\hline $\begin{array}{l}\text { Section B: Role of managers in ensuring effectiveness of the } \\
\text { performance management system }\end{array}$ & $N$ & Mean, $\bar{x}$ & $\begin{array}{c}\text { Standard } \\
\text { deviation, } \sigma\end{array}$ & $\begin{array}{l}\text { Standard error } \\
\text { of the mean }\end{array}$ \\
\hline Q. Performance review by line manager & 313 & 3.42 & 1.248 & 0.071 \\
\hline Q. Knowledge of manager in implementing PMS & 313 & 3.45 & 1.168 & 0.066 \\
\hline Q. Application of PMS by manager in accordance with institutional policy & 313 & 3.49 & 1.115 & 0.063 \\
\hline Q. Evidential justification of my performance to manager for rating & 313 & 3.74 & 1.115 & 0.063 \\
\hline Q. Objectivity of my rating by manager & 313 & 3.4 & 1.139 & 0.064 \\
\hline Q. Rating by manager is subjective & 313 & 2.2 & 1.089 & 0.062 \\
\hline Q. Explanation of rating outcomes by manager & 313 & 3.29 & 1.164 & 0.066 \\
\hline Q. Rating based on performance rather than personality & 313 & 3.47 & 1.138 & 0.064 \\
\hline Q. Consistency of rating across board & 313 & 3.03 & 1.167 & 0.066 \\
\hline Q. Opportunity to clarify rating by manager & 313 & 3.77 & 1.028 & 0.058 \\
\hline
\end{tabular}

PMS, performance management system. 
This deduction was derived from the following statistical results obtained from the analysis of respective questionnaire items: $\bar{x}=3.4$ and $\sigma=1.139 ; \bar{x}=3.74$ and $\sigma=1.149 ; \bar{x}=3.4$ and $\sigma=1.139$. However, analysis of a related questionnaire item indicated that managers indeed based their performance assessment essentially on the evidence of their work performance rather than individual employee's personality. This conflicting outcome was derived from the following statistical results, which demonstrated a mean of $\bar{x}=3.29$ and a corresponding standard deviation of $\sigma=1.164$.

According to Flaniken (2009) and Aguinis (2013), raters should focus on the standard of work performance relative to predetermined goals without consideration for extraneous issues (e.g. personal relationship with the employee). Aguinis (2013) further reiterated the need for managers to avoid destructive criticism when reviewing employee performance, no matter how poor they perceive the employee's performance to be, as this could trigger negative feelings that could result in interpersonal conflict in the workplace.

Any open appraisal system should make provisions for employees to ask raters for explanation and perhaps justification of the rating outcomes. In this article, respondents could not confirm whether they received any form of explanation or justification for their rating outcomes from their managers. This assertion was predicated on the strength of statistical results, which showed a mean and standard deviation that are slightly above average $(\bar{x}=3.29$ and $\sigma=$ $1.164)$ in respect of the rating outcome by managers. Literature (e.g. Karuhanga 2010) recorded lack of provision of adequate feedback to employees by raters as a major challenge in PMSs. This failure on the part of management is contrary to the position canvassed by Aguinis, Joo and Gottfredson (2011) to the effect that a PMS serves as an important two-way communication device, as it clarifies the types of behaviours and results that are valued and rewarded by the organisation. Consistency in the application of performance criteria across the board constitutes an important consideration regarding the integrity of a PMS. This attribute was tested in this article and the results indicated a non-commitment (i.e. no confirmation) by the respondents regarding the consistent application of the PMS criteria to all participants given statistical results of $\bar{x}=3.03$ and $\sigma=1.167$, respectively. This result could be informed by the confidential nature of the PMS, which was conducted on a one-on-one basis between individual employees and their managers. Therefore, it is not easy for individual employees to compare performance ratings among themselves. This reasoning could be sustained by Aguinis's (2013) recommendation, which emphasised the need for managers to always assure individual employees about the confidentiality of personal information collected from them.

There was a low level of participation by respondents in setting the goals of performance management. This was evident in the statistical results of $\bar{x}=3.23$ and $\sigma=1.23$, suggesting that a little above average of the respondents indicated their participation in the process. Given these results, it cannot be said that the entire system was that of 'command and control'.

A participatory PMS is an important motivational tool for employees in achieving predetermined organisational goals (Gruman \& Saks, 2011; Locke \& Latham, 2002). Notwithstanding the level of employees' participation in the goal-setting process, respondents clearly understood their responsibilities regarding the performance goals and standards $(\bar{x}=3.46$ and $\sigma=1.167)$. This outcome is consistent with Aguinis (2013) that managers should discuss key or broad areas of job responsibilities with individual employees for the purpose of performance accountability. It has been theoretically established (Locke \& Latham, 1990) that managers should set challenging but achievable goals. Goal setting should be pitched at a level that commensurates with the hierarchical position of individual employees within the organisation. In this article, there was indication that performance goals and standards were at appropriate levels of responsibility. This statement was supported with a statistical result $\bar{x}=3.28$ and $\sigma=1.178$, leading to the conclusion that most academics considered their performance goals and standards as achievable and having been set at an acceptable level of responsibility.

Pienaar and Bester (2007) reported that academics considered PMSs to lack validity, that is, they do not measure all aspects of the job they are supposed to measure. This shortcoming was reiterated by Aguinis et al. (2011) that good and credible PMSs should evaluate all major job responsibilities, including behaviours and results. However, majority $(\bar{x}=3.45$ and $\sigma=1.270)$ of the respondents in this article indicated that not all tasks performed by them were taken into consideration when setting performance goals, thus adversely affecting their ratings. Similarly, a large percentage

TABLE 3: Results of one-sample $t$-test statistics for Section $C$ of the measuring instrument.

\begin{tabular}{|c|c|c|c|c|}
\hline Section C: Satisfaction with performance goals and standard setting & $N$ & Mean, $\bar{x}$ & Standard deviation, $\sigma$ & Standard error of the mean \\
\hline Q. Satisfaction with involvement in setting goals and standard & 313 & 3.23 & 1.23 & 0.07 \\
\hline Q. Clarity of performance goals and standards & 313 & 3.46 & 1.168 & 0.066 \\
\hline Q. Appropriateness of performance goals and standards & 313 & 3.28 & 1.178 & 0.067 \\
\hline Q. Accuracy of tasks in relation to goal setting & 313 & 3.45 & 1.270 & 0.72 \\
\hline Q. Rating based on agreed goals & 313 & 3.34 & 1.124 & 0.064 \\
\hline Q. Goals and standards reflect the most important factors in my job & 313 & 3.23 & 1.258 & 0.071 \\
\hline Q. Unilateral imposition of performance goals and standards by management & 313 & 3.23 & 1.312 & 0.074 \\
\hline Q. Flexibility of performance goals & 313 & 3.13 & 1.158 & 0.065 \\
\hline
\end{tabular}


of the respondents reported failure of the PMS to capture their entire workload as evidenced in the statistical outcome $(\bar{x}=2.37$ and $\sigma=1.27)$. Barret and Barret (2008) reported a similar finding in their study. They further report that academics who were surveyed worked long hours and during weekends with their extra efforts not captured in the performance rating. Molefe (2010) further submitted that PMSs are likely to be resisted by academics if they do not take into account the teaching workload or distribution of the workload between members of departments.

However, respondents conceded that management did not deviate from predetermined goals and standards in rating their performance. This response was underscored with statistical results of $\bar{x}=3.34$ and $\sigma=1.124$ and the outcome is consistent with the submission of consistency with Aguinis (2013), who emphasised that a good PMS should review the extent to which the desired behaviours are being displayed, and whether the desired results have been achieved as agreed upon in the performance agreement. However, flexibility was built around the application of the PMS to enable amendments to performance goals and standards should there be changes in the nature of tasks performed in the future.

The respondents were asked to state whether the PMS respects their independence and freedom regarding their work as academics. One of the core values that academics considered as crucial and non-negotiable for a successful career is the issue of academic freedom and work autonomy. Barret and Barret (2008) asserted that academics have a high regard for work autonomy and a fairly well-developed cynicism about managerial practices, including performance management. Consistent with Barret and Barret's assertion, the results of this article $(\bar{x}=2.67$ and $\sigma=1.297)$ showed widespread resentment among respondents who considered PMS as an orchestrated design by management to undermine their academic freedom and work autonomy. This finding also concurred with that of Pityana (2004) who reiterated that academic duties have long been defined by work autonomy and academic freedom, but such rubrics are now being dictated by other parties in line with the dictate of market economy and other considerations. The perception of management infringement (through PMS) of academic freedom and work autonomy did negatively affect respondents' attitude towards their work. Results obtained in this study $(\bar{x}=2.61$ and $\sigma=1.342)$ alluded to this statement. Luthra and Jain (2012) provided literature support for this finding by stating that PMS will not achieve its intended purpose if employees lack faith in its implementation.

A major argument in favour of PMS is its inherent ability to fairly distribute organisational rewards. This argument is theoretically supported by Adams' equity theory (1963) which postulated that people compare their work-input (contribution) and outcomes (rewards or bonuses) with those of other workers in order to determine the level of inequity or equity. The outcome of such equity analysis provides an employee with a motivational or attitudinal platform towards the achievement of organisational goals. The performance bonus associated with goal achievement failed to motivate respondents in this study as demonstrated by the statistical results $(\bar{x}=2.86$ and $\sigma=1.343)$. Luthra and Jain (2012) contended that employees may perceive that the PMS is unfair in distributing rewards to better performers. Such perception by under-performers may lead to a situation where they have them to deal with the perceived imbalance between efforts and rewards by altering their performance (putting in less effort).

Two reasons can be attributed to the results presented above. Firstly, employees could consider the bonus as not attractive enough, as articulated by the expectancy theory (Vroom, 1964), to the extent that employees will only work harder if the reward promised is attractive. Secondly, rewards are a great source of motivation for employees, but they can prove to decrease motivation in circumstances where those employees having poor performance records are equally rewarded as high performers (Saeed \& Shahbaz, 2011). However, we could not find statistical confirmation as to whether performance bonus motivated poor performers to work harder in order to receive a bonus in the future. The statistical mean of $\bar{x}=2.73$ and a standard deviation of $\sigma=1.276$ suggest that respondents were not motivated by the performance bonus to strive for excellence. Vroom's (1964) expectancy theory posits that employees first assess the degree to which improved job performance is expected to lead to desired outcomes. This finding may be explained within the context of an earlier finding in this article, which indicated that the criteria used in calculating performance bonuses by management are not fair as represented by a statistical mean of $\bar{x}=2.69$ and a corresponding standard deviation of $\sigma=1.191$. A possible reason for this outcome could be lack of proper understanding by academic staff of how performance bonuses are calculated as literature

TABLE 4: Results of one-sample t-test statistics for Section D of the measuring instrument.

\begin{tabular}{|c|c|c|c|c|}
\hline Section D: Satisfaction with performance rating and bonus payment & $N$ & Mean, $\bar{x}$ & Standard deviation, $\sigma$ & Standard error of the mean \\
\hline Q. Recognition of academic freedom and work autonomy by the PMS & 313 & 2.67 & 1.297 & 0.073 \\
\hline Q. Attitudinal motivation by the PMS & 313 & 2.61 & 1.342 & 0.076 \\
\hline Q. Consideration of workload by the PMS & 313 & 2.37 & 1.27 & 0.072 \\
\hline Q. All elements of work accounted for during performance review & 313 & 2.74 & 1.302 & 0.074 \\
\hline Q. Fair criteria in calculating performance bonus & 313 & 2.69 & 1.191 & 0.067 \\
\hline Q. Performance bonus motivates towards achieving excellence & 313 & 2.86 & 1.343 & 0.076 \\
\hline Q. Poor performers motivated to improve by performance bonus & 313 & 2.73 & 1.276 & 0.072 \\
\hline Q. Fair performance rating & 313 & 3.5 & 1.11 & 0.063 \\
\hline
\end{tabular}

PMS, performance management system. 
revealed that employees generally have a negative perception of how PMSs distribute rewards (Luthra \& Jain, 2012).

To conclude our discussion of findings, a greater percentage of respondents indicated their general satisfaction with the outcome of their latest performance evaluation which they described as fair. This position was derived from a statistical mean of $\bar{x}=3.5$ and a standard deviation of $\sigma=1.111$, thus confirming earlier findings reported in this article to the effect that raters were knowledgeable in implementing the PMS and that they are rated strictly based on performance rather than personality. Therefore, it can be concluded that PMS in the case institution is more fairly implemented than what is obtainable in other organisations. For example, a study by Flaninken (2009) reported lack of credibility in the implementation of PMS in the organisation that was surveyed. The outcome of another study conducted by Gallup in India in 2010 also indicated that Indian employees, particularly those with 3-10 years' tenure in an organisation, strongly feel that most PMSs are not capable of distinguishing superior performance; therefore, they found such systems to be unfair (Luthra \& Jain, 2012).

\section{Conclusion}

This article highlighted the perception and experiences of academic staff regarding the implementation of PMS in an ODL higher educational institution in South Africa. While the PMS was designed as a mechanism through which productivity of academic staff could be objectively determined and managed, the measurement criteria used in the PMS failed to adequately capture all the tasks performed by academics. This raises concern about the validity of the PMS and its fairness in the equitable distribution of organisational outcomes. Implementation of PMS in institutions of higher learning is not entirely undesirable if properly designed and effectively managed. While it is imperative to adopt a participative approach in its design, administration of the system should also be transparent. The outcomes of this study provide an impetus for improving existing and future PMS implementation by management.

\section{Acknowledgements}

We want to sincerely thank the reviewers for painstakingly going through the manuscript and making constructive suggestions. Their suggestions have assisted us tremendously in improving the quality of this manuscript. We are truly indebted to them

\section{Competing interests}

The authors declare that they have no financial or personal relationships which may have inappropriately influenced them in writing this article.

\section{Authors' contributions}

E.M.M. conceptualised the study, provided literature review and collected primary data. M.O.S. supervised the study and assisted in methodology, data analysis and wrote the manuscript.

\section{References}

Adams, J.S. (1963). Towards an understanding of inequality. The Journal of Abnorma Social Psychology, 67(5), 422-436. http://dx.doi.org/10.1037/h0040968

Aguinis, H. (2013). Performance management (2nd edn.). Upper Saddle River, NJ: Pearson Prentice Hall.

Aguinis, H., Joo, H., \& Gottfredson, R.K. (2011). Why we hate performance management - And why we should love it. Business Horizon, 54(6), 503-507. http://dx.doi.org/10.1016/j.bushor.2011.06.001

Armstrong, M. (2009). Handbook of human resource management practice (11th edn.). London: Kogan Page.

Atkinson, C., \& Shaw, S. (2006). Managing performance. In R. Lucas, B. Lupton, \& H. Mathieson (Eds.), Human resource management in an international context (pp. 173-198). London: CIPD.

Baldwin, S. (2006). Organisational justice. HR Network Paper MP73. Brighton: Institute for Employment Studies.

Barret, L., \& Barret, P., (2008). The management of academic workload: Full report. London: Leadership Foundation for Higher Education.

Bititci, U.S., Mendibil, T.K., Nudurupati, S.S., Garengo, P., \& Turner, T.J. (2004). The interplay between performance measurement, organisational culture and management styles. Measuring Business Excellence, 8(3), 28-41. http://dx.doi. management styles. Measuring Busin
org/10.1108/13683040410555591

Bogt, H.J., \& Scapens, R.W. (2011, September). The management of performance in universities - NPM and some of its effects. Paper presented at the EGPA Conference, Bucharest.

Bowman, J. (1994). At last, an alternative to performance appraisal. Total quality management. Public Administration Review, 54, 129-136. http://dx.doi.org/10. 2307/976521

Bryman, A., \& Bell, E. (2011). Business research methods (3rd edn.). New York: Oxford University Press.

Chawla, D., Chindra, S., \& Pandey, V. (2013). Census and sample methods. Retrieved January 17, 2015, from http://www.slideshare.net/SunilChichra/introduction28293803

Coleman, T.G. (2012). A model for improving the strategic measurement and management of policing: The police organizational performance index (POPI). Unpublished doctoral dissertation, University of Regina, Saskatchewan.

Cooper, D.R., \& Schindler, P.S. (2001). Business research methods. New York: McGrawHill.

Daley, D. (1998). Designing effective performance appraisal systems. In S. Condrey (Ed.), Handbook of human resource management in government (3rd edn., pp. 555-586). San Francisco, CA: Jossey-Bass.

Decramer, A., Christiaens, J., \& Vanderstraeten, A. (2007, August). Individua performance management in higher education institutions. Paper presented at the 29th Annual EAIR Forum, Innsbruck.

Farndale, E., Van Ruiten, J., Kelliher, C., \& Hope-Hailey, V. (2011). The influence of perceived employee voice on organizational commitment: An exchange perspective. Human Resource Management, 50(1), 113-129. http://dx.doi.org/ 10.1002/hrm.20404

Flaniken, F.W. (2009). Performance appraisal systems in higher education: An exploration of Christian institutions. Unpublished doctoral degree thesis, University of Central Florida, Orlando, FL.

Floyd, J., \& Fowler, J.R. (2013). Survey research methods (5th edn.). Thousand Oaks: Sage.

Fox, C., \& Shirkey, K. (1997). Employee performance appraisal: The keystone made of clay. In C. Ban, \& N. Riccucci (Eds.), Public personnel management (pp. 189-204). New York: Longman.

Greenberg. (1990). Organisational justice: Yesterday and tomorrow. Journal of Management, 16(2), 399-432. http://dx.doi.org/10.1177/014920639001600208

Gruman, J.A., \& Saks, A.M. (2011). Performance management and employee engagement. Human Resource Review, 21(2), 123-136. http://dx.doi.org/10. 1016/j.hrmr.2010.09.004

Hainess, V.Y., III, \& St-Onge, S. (2012). Performance management effectiveness: Practices or context?. The International Journal of Human Resource Management, 23(6), 1158-1175. http://dx.doi.org/10.1080/09585192.2011.561230

Harding, R. (2006). Social entrepreneurship monitor. London: Global Entrepreneurship Monitor.

Hatch, M.J., \& Cunliffe, A.L. (2006). Organisation theory: Modern, symbolic, and postmodern perspectives (2nd edn.). Oxford: Oxford University Press.

Hawke, L. (2012). Australian public sector performance management: Success or stagnation? Journal of Productivity and Performance Management, 61(3), 310-328.

Hill, C. (2010). External pressures bring changes to higher education. Retrieved October 31, 2012, from http://www.facultyfocus.com/articles/distance-learning/ external-pressures-bringchanges-to-higher-education/

Holland, K. (2006, September 10). Performance reviews: Many need improvement. The New York Times. Retrieved from http://www.nytimes.com/2006/09/10/ business/yourmoney/10mgmt.html?_r=0

Hudzik, J.K. (2011). Comprehensive internationalization: From concept to action. Washington, DC: NAFSA. The Association of International Educators.

Imran, H., Arif, I., Cheema, F., \& Azeem, M. (2014). Relationship between job satisfaction, job performance, attitude towards work, and organizational commitment. Entrepreneurship and Innovation Management Journal, 2(2), 135-144. 
Islam, R., \& Rasad, S.B.M. (2006). Employee performance evaluation by AHP: A case study. Asia Pacific Management Review, 11(3), 163-176.

Junais, P.K. (2012). Performance appraisal. Retrieved June 30, 2016, from http://www. slideshare.net/NITCALICUT_SOMS/performance-appraisal-15464013

Kandula, S.R. (2006). Performance management strategies-interventions-drivers. New Delhi: PHI Learning Pvt Ltd.

Karim M.O. (2015). Assessing the influential behavioral factors of performance management systems. Journal of Strategy and Performance Management, 3(1) 4-16.

Karuhanga, B.M. (2010, August). Challenges of performance management in universities in Uganda. Paper presented at the International Research Symposium in Service Management, Mauritius.

Kavanagh, P., Benson, J., \& Brown, M. (2007). Understanding performance appraisal fairness. Asian Pacific Journal of Human Resource Management, 45(2), 132-150. http://dx.doi.org/10.1177/1038411107079108

Kim, P.S. (2011, April). Performance management and appraisal. Paper delivered at the CEPA Meeting, New York.

Locke, E.A., \& Latham, G.P. (1990). A theory of goal setting and task performance. Upper Saddle River, NJ: Prentice Hall.

Luthra, P., \& Jain, M. (2012). India's performance management problem. Gallup Business Journal (Online). Retrieved February 14, from http://businessjourna. gallup.com/content/153278/india-performance management-problem.aspx

Maimela, E.E. (2015). Academic staff perception of performance management: A case study of an open distance learning institution. Unpublished master of commerce dissertation, University of South Africa, Pretoria, South Africa.

Mapesela, M.L.E., \& Strydom, F. (2004, November). Performance management of academic staff in South African higher education system: A developmental project. Paper presented at the OECD Conference on Trends in the Management of Human Resource in Higher Education, University of the Free State, Bloemfontein South Africa.

Martz, B., McKenna, J., \& Siegall, M. (2001). Applying a standard performance mode to a university setting. Business Process Management Journal, 7(2), 100-113. http://dx.doi.org/10.1108/14637150110389425

Molefe, G.N. (2010). Performance measurement dimensions for lecturers at selected universities: An international perspective. South African Journal of Human Resource Management, 8(1), 1-13.

Molefe, G.N. (2012). Performance measurement model and academic staff: A survey at selected universities in South Africa and abroad. African Journal of Business Management, 6(15), 5249-5267.

Nunnally, J.C. (1978). Psychometric theory (2nd edn.). New York: McGraw-Hill.

Ogbonna, E. (2007). Managing culture: Fantasy or reality? Human Resource Journal, 3(2), 42-54. http://dx.doi.org/10.1111/j.1748-8583.1992.tb00309.x

Osei-Owusu, M. 2013. Performance management in Higher Education Institution Review of experience, performance Management in Higher Education Institution Retrieved June 24 2015, from http://ssrn.com/abstract=2240895

Parsons, P.G., \& Slabbert, A.D. (2001). Performance management and academic workload in higher education. South African Journal of Higher Education, 15(3), 74-81. http://dx.doi.org/10.4314/sajhe.v15i3.25328

Perry, J. (1991). Linking pay to performance. The controversy continues. In C. Ban, \& N. Riccucci (Eds.), Public personnel management (pp. 73-86). White Plains, NY: Longman.

Pienaar, C., \& Bester, C.L. (2007). The retention of academics in the early career phase. South African Journal of Human Resource Management, 6(2), 32-41.

Pieters, M. (2009). The textbook for personnel management. Cape Town: Kagiso Higher Education.
Pityana, N.B. (2004, April). Higher education in South Africa: Future perspectives. Keynote address delivered at Bill Venter/Altron Literacy Awards 2003, Johannesburg.

Robinson, H.S., Carrillo, P.M., Anumba, C.J., \& A-Ghassani, A.M., 2005, Review and implementation of performance management models in construction engineerin organizations. Construction Innovation: Information, Process, Management, 5(4), 203-217. http://dx.doi.org/10.1108/14714170510815258

Ryan, R.M., \& Deci, E.L. (2000). Intrinsic and extrinsic motivations: Classic definitions and new directions. Contemporary Educational Psychology, 25, 54-67. http:// dx.doi.org/10.1006/ceps.1999.1020

Saeed, M.K., \& Shahbaz, N. (2011). Employee perceptions about the effectiveness of performance appraisals: The case of Pakistan. SIU Journal of Management, 1(1) $58-75$.

Schultz, H., Bagraim, J., Potgieter, T., Viedge, C. \& Werner, A. (2003). Organisationa behaviour: A contemporary South African perspective. Pretoria: Van Schaik Publishers.

Shields, J. (2008). Managing employee performance and reward: Concepts, practices, strategies. New York: Cambridge University Press.

Shishkina, V. (2008). New public management strategies: Implications for universities in emerging economies. Unpublished master's thesis, Blekinge Institute of Technology, Karlskrona, Sweden.

Solomons, N. (2006). A critical evaluation of the performance management system used by Nampak research and development. Unpublished MBA dissertation, Nelson Mandela Metropolitan University, Port Elizabeth, South Africa.

Sousa, C.A.A., De Nijs, W.F., \& Hendriks, P.H.J., 2010, Secrets of the beehive: Performance management in university research organisations. Human Relations, 16(9), 1439-1460. http://dx.doi.org/10.1177/0018726709357083

South African Institute for Distance Education (SAIDE). 2009. SAIDE policy on open educational resources. Retrieved November 23, 2012, from https://www.google. $\mathrm{com} / \mathrm{search}$ ?sourceid=navclient\&ie $=U T F-8 \& \mathrm{rl}=1 T 4 P$ LXB enZA595ZA596\& $q=S A$ $\mathrm{DE}+\% 28$ South+African+Institute+for+Distance+Education $\% 29 .+2009$. + SAIDE+pol icy+on+open+educational+resources

Stanton, P., \& Nankervis, A. (2011). Linking HRM, performance management and organisational effectiveness: Perceptions of managers in Singapore. Asia Pacific Review, 17(1), 62-84.

Tam, W.H.K. (2008). Academics' perspectives of performance management in a British university context. Unpublished PhD thesis, University of Leicester, Leicester, United Kingdom.

Taticchi, P., Balachandran, K., \& Tonelli, F., 2012, Performance measurement and management systems: State of the art, guidelines for design and challenges. Measuring Business Excellence, 16(2), 4. http://dx.doi.org/10.1108/136830 41211230311

Toppo, L., \& Prusty, T. (2012). From performance appraisal to performance management. Journal of Business and Management, 3(5), 1-6. http://dx.doi. management. Journal of Bus

Türk, K. (2007). Performance appraisal and the compensation of academic staff in the University of Tartu. Baltic Journal of Management, 3(1), 40-54. http://dx.doi. org/10.1108/17465260810844257

Tustin, D.H., Lighelm, A.A., Martins, J.H., \& Van Wyk, H. de J. (2005). Marketing research in practice. Pretoria: Unisa Press.

Vroom, V.H. (1964). Work and motivation. San Francisco, CA: Jossey-Bass.

Willaert, P., \& Willems, J. (2006). Process performance measurement: Identifying KPIs that link process performance to company strategy. Emerging Trends and that link process performance to company strategy. Emerging
Challenges in Information Technology Management, 1(2), 740-744.

Zeleza, P.T. (2012, March). Internationalization in higher education: Opportunities and challenges for the knowledge project in the global south. Paper presented at A SARUA Leadership Dialogue on Building the Capacity of Higher Education to Enhance Regional Development, Maputo, Mozambique. 